\title{
Investigation of Interaction of Some Chalcones and Cyclic Chalcone Analogues with Outer Mitochondrial Membrane by UV-VIS and Fluorescence Spectroscopy
}

\author{
Vladimíra Tomečková ${ }^{1}$, Miroslava Štefanišinová ${ }^{1}$, Beáta Veliká ${ }^{1}$, Krisztina Fodor ${ }^{2}$, Pal Perjési $^{2}$, \\ Marek Stupák ${ }^{1}$, Juraj Guzy ${ }^{1}$, Štefan Tóth Jr. ${ }^{1}$, Tímea Pekárová ${ }^{1}$ \\ ${ }^{1}$ Department of Medical Chemistry, Biochemistry and Clinical Biochemistry, Faculty of Medicine, Pavol Jozef Šafárik University in \\ Košice, Košice, Slovakia; ${ }^{2}$ Institute of Pharmaceutical Chemistry, Faculty of Medicine, University of Pécs, Pécs, Hungary. \\ Email: vladimira.tomeckova@upjs.sk
}

Received June $1^{\text {st }}, 2013$; revised July $11^{\text {th }}, 2013$; accepted July $21^{\text {st }}, 2013$

Copyright (C) 2013 Vladimíra Tomečková et al. This is an open access article distributed under the Creative Commons Attribution License, which permits unrestricted use, distribution, and reproduction in any medium, provided the original work is properly cited.

\begin{abstract}
Interaction of the synthetic chalcones $(\mathbf{1 b}, \mathbf{1} \mathbf{c})$ and their cyclic analogues $(\mathbf{2 b}, \mathbf{2} \mathbf{c})$ with bovine (BSA) and human serum albumin (HSA) as well as with rat liver mitochondria (RLM) was studied by fluorescence spectroscopy. The maxima of emission fluorescence spectra were changed only in the case of $\mathbf{2 b}$ and $\mathbf{2 c}$ during interaction with BSA, HSA as well as mitochondrial outer membrane showing a slight hypsochromic shift and decrease of fluorescence. Interaction of the methoxy-(1b,2b) and the dimethylamino-substituted $(\mathbf{1 c}, \mathbf{2} \mathbf{c})$ compounds with outer mitochondrial membrane were studied by fluorescence polarization. Fluorescence polarization of $\mathbf{1 b}$ in the presence of the two proteins and mitochondria was found to be unchanged. Under similar conditions $(\mathbf{2 b}, \mathbf{1} \mathbf{c}, \mathbf{2 c})$ showed continuously increasing fluorescence polarization signal during the 30 minute period of investigations. Since fluorescence polarization supposes that as a result of binding these substances to proteins and lipids. Compound $\mathbf{2 c}$ displayed a continuous increase of fluorescence polarization signal in the presence of proteins (BSA, HSA), yeast cytoplasm (YC) and mitochondria (YM and RLM). This compound displayed a significant cytotoxic effect. This pattern of interaction with proteins might be one of the contributing vectors of the observed cytotoxicity against several human carcinoma cell lines.
\end{abstract}

Keywords: Chalcones; Yeast Cytoplasm; Yeast Mitochondria; Rat Liver Mitochondria; Fluorescence Polarization; Fluorescence Synchronous Fingerprint

\section{Introduction}

Flavanones, flavonols, chalcones and dihydrochalcones are biochemically related compounds sometimes being present in food at a dietary significant concentration [1]. Flavonoids, chalcones and chalcone derivatives have been reported to display among others e.g. cytotoxic, antitumor, antiinflammatory, immunosuppressive, antiplasmodial and antioxidant properties [2-4]. Among the naturally occurring chalcones and their synthetic analogues several compounds displayed antineoplastic activity [4]. Recently we have investigated in vitro antineoplastic activity of several synthetic chalcones and cyclic chalcone analogues [5-7]. Among the compounds investigated E-2-(4'-methoxybenzylidene)-1-benzosuberone (2b) and E-2-(4'-dimethylaminobenzylidene)-1-benzosuberone (2c) (Figure 1) had the greatest tumour cyto- toxicity [5].

Earlier results suggested that the chalcone derivatives exert their biological activities through noncovalent interactions with cellular macromolecules [5-7]. UV-VIS study of methoxy and dimethylamino substituted chalcones and cyclic chalcone analogues with bovine (BSA) and human serum albumin (HSA) resulted in a slight hypsochromic shift of $\mathbf{2 b}$ and $\mathbf{2 c}$ indicating changing the polar environment to a less polar one [8]. Such an observation is in accord with interaction of the molecules with the hydrophobic binding site(s) of the two proteins.

While investigating the mechanism of cytotoxicity of the compounds, effect on mitochondrial outer membrane of some methyl- and methoxy-substituted E-2-arylmethylene-1-tetralones and E-2-arylmethylene-1-benzosuberones were investigated by fluorescence spectroscopy [9]. It was found that the most cytotoxic benzo- 


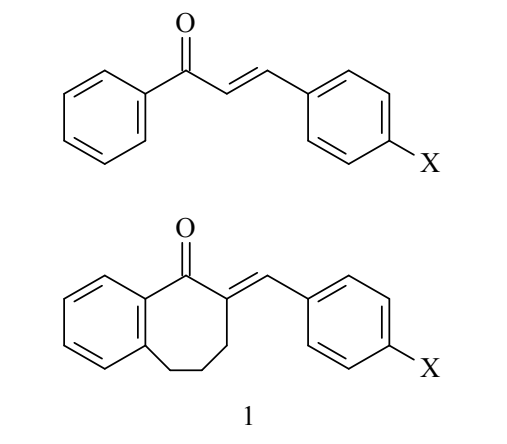

a) $\mathrm{X}=\mathrm{H} \quad$ b) $\mathrm{X}=\mathrm{OCH}_{3} \quad$ c) $\mathrm{X}=\mathrm{N}\left(\mathrm{CH}_{3}\right)_{2}$

Figure 1. Structure of chalcones (1) and E-2-arylidenebenzosuberones (2).

suberone derivative (2b) displayed a continuous increase of fluorescence polarization in the presence of rat liver mitochondria [9].

As a continuation of our work aims at gaining a better insight of interaction of the compounds with biological macromolecules, we investigated interaction of methoxy and dimethylamino-substituted chalcones $(\mathbf{1 b}, \mathbf{c})$ and (E)-2-arylmethylene-1-benzosuberones (2b,c) with BSA, HSA, yeast cytoplasm (YC) as well as with yeast (YM) and rat liver mitochondria (RLM) by fluorescence spectroscopic methods. Since FP is most readily applicable to the analysis of the binding interaction between smallmolecular-mass compound and a receptor molecule, we considered applying this technique to the analysis of chalcones (1b,c) and (E)-2-arylmethylene-1-benzosuberones $(\mathbf{2 b}, \mathbf{c})$ by investigating their interaction with BSA, HSA, yeast cytoplasm, yeast mitochondria and rat liver mitochondria. In practice, low-molecular-weight fluorophores are very flexible and rotate rapidly in solution, depolarizing the plane-polarized light. On the other hand, large fluorescently labelled molecules tumble more slowly; thus, the polarization of the light remains relatively constant between excitation and emission states. Therefore, low-molecular-mass compounds have low polarization values while high-molecular-weight compounds show greater polarization values.

\section{Materials and Methods}

Compounds $\mathbf{1 b}, \mathbf{c}$ and $\mathbf{2 b}, \mathbf{c}$ (Figure 1) were synthesized, and their structures were characterized as described before $[5,10]$. Their structures were characterized by IR and ${ }^{1} \mathrm{H}$ NMR spectroscopy. Their purity was checked by TLC (thin layer chromatography) and GC (gas chromatography) methods $[5,10]$. Other chemicals used were of the analytical grade available and, if not otherwise specified, purchased from Sigma-Aldrich (Hungary, Budapest) or Serva (Heidelberg, Germany). Compounds $\mathbf{1}$ and $\mathbf{2}$ were dissolved in DMSO immediately before use. The respira- tion medium $(\mathrm{pH} 7.4)$ containing EDTA $(0.78 \mathrm{mM})$, $\mathrm{MgCl}_{2}(6 \mathrm{mM})$, TRIS $\mathrm{HCl}(4 \mathrm{mM}), \mathrm{KCl}(0.08 \mathrm{M})$, $\mathrm{K}_{2} \mathrm{HPO}_{4}(0.3 \mathrm{M})$ and $\mathrm{KH}_{2} \mathrm{PO}_{4}(0.3 \mathrm{M})$ was prepared by bidistilled water. Male Wistar rats (Velaz, Praha, Czech Republic) weighing 250 - $300 \mathrm{~g}$ fed on a standard laboratory diet and tap water were used in the experiment. Adhering to procedures approved by the University of Košice Animal Care and Use Committee, the animals were sacrificed by cervical displacement and decapitation. Mitochondria from rat liver were isolated according to Johnson and Lardy [11]. The protein content of the isolated mitochondria (RLM) was determined by the Bradford method [12]. Subcellular fractionation of strain BY4741, wilde type on cytoplasm (YC) and mitochondria (YM) has been performed by established procedure for the yeast Saccharomyces cerevisiae according Zinser and Daum [13] in Graz, Austria. The protein content of the isolated mitochondria was determined by the method of Lowry et al. [14]. Isolated yeast cytoplasm and mitochondria were diluted by $100 \mathrm{mM}$ TRIS/HCl, $\mathrm{pH} 7.4$ to the final concentration $2 \mathrm{mg} / \mathrm{ml}$. For fluorescence measurements the suspension of BSA, HSA, RLM, YC and YM were diluted with respiration medium containing 1 $\mathrm{mM}$ sodium succinate to the final concentration of 2 $\mu \mathrm{g} / \mathrm{ml}$. The fluorescence spectra and fluorescence polarization (FP) measurements were run on a Perkin-Elmer Model LS 55 luminescence spectrometer using $1 \mathrm{~cm}$ path length quartz cuvettes at ambient temperature. The wavelength scan speed of both monochromators was 200 or $1200 \mathrm{~nm} / \mathrm{min}$. Setting of instruments excitation slit was $5 \mathrm{~nm}$ and emission slit was $10 \mathrm{~nm}$. Data processing was managed by the FL Winlab (Perkin-Elmer) software package. Fluorescence polarization (FP) was defined as $\mathrm{FP}=(\mathrm{V}-\mathrm{H})^{*} \mathrm{G} /(\mathrm{V}+\mathrm{H})^{*} \mathrm{G}$, where $\mathrm{V}$ and $\mathrm{H}$ are the intensities of the vertical and horizontal emission components respectively, when vertically polarized excitation is used $[15,16]$. The grating correction factor for the optical system $(G)$ is given by the ratio of the vertically to the horizontally polarized emission components when the excitation light is polarized in the horizontal direction [16]. Maxima of excitation and emission fluorescence spectra (Table 1) have been determined by recording excitation and emission fluorescence spectra of $1 \times 10^{-5}$ $\mathrm{M}$ of $\mathbf{2 b}$ and $\mathbf{2 c}$ in respiration medium containing $1 \%$ DMSO and $1 \mathrm{mM}$ sodium succinate. Synchronous fluorescence scan (SFS) spectra of (2b) and (2c) were measured in respiration medium containing $1 \%$ DMSO and 1 $\mathrm{mM}$ sodium succinate with the fluorescent maxima of (2b) at $(\Delta \lambda=30 / 280$ and $50 / 365 \mathrm{~nm})$ and of $(\mathbf{2 c})$ at $(\Delta \lambda=$ $100 / 415 \mathrm{~nm}$ ) are graphical drawing of 10 scans of simple fluorescence synchronous fluorescence spectra together placed in space with the increment 20 (Figures $\mathbf{2}$ and $\mathbf{3}$ ). Each scan has been run by setting constant differences 
Table 1. Characteristic fluorescence parameters of compounds $1 \mathrm{~b}, 1 \mathrm{c}, 2 \mathrm{~b}$, and $2 \mathrm{c}$ determined in respiration medium containing $1 \%$ DMSO and $1 \mathrm{mM}$ sodium succinate.

\begin{tabular}{ccccccc}
\hline Compound & $\begin{array}{c}\text { Concentration } \\
(\mathrm{nmol} / \mathrm{ml})\end{array}$ & $\begin{array}{c}\text { Excitation maximum } \\
\lambda_{\mathrm{ex}}(\mathrm{nm})\end{array}$ & $\begin{array}{c}\text { Fluorescence intensity } \\
\mathrm{F}_{\mathrm{ex}}\end{array}$ & $\begin{array}{c}\text { Emission maximum } \\
\lambda_{\mathrm{em}}(\mathrm{nm})\end{array}$ & $\begin{array}{c}\text { Fluorescence intensity } \\
\mathrm{F}_{\mathrm{em}}\end{array}$ & $\begin{array}{c}\text { Fluorescence polarization } \\
\text { FP }\end{array}$ \\
\hline $\mathbf{1 b}$ & 10 & 363 & 583 & 485 & 586 & 0.398 \\
$\mathbf{2 b}$ & 10 & 365 & 112 & 417 & 114 & 0.563 \\
$\mathbf{1 c}$ & 10 & 477 & 708 & 542 & 719 & 0.04 \\
$\mathbf{2 c}$ & 10 & 415 & 580 & 516 & 590 & 0.090 \\
\hline
\end{tabular}
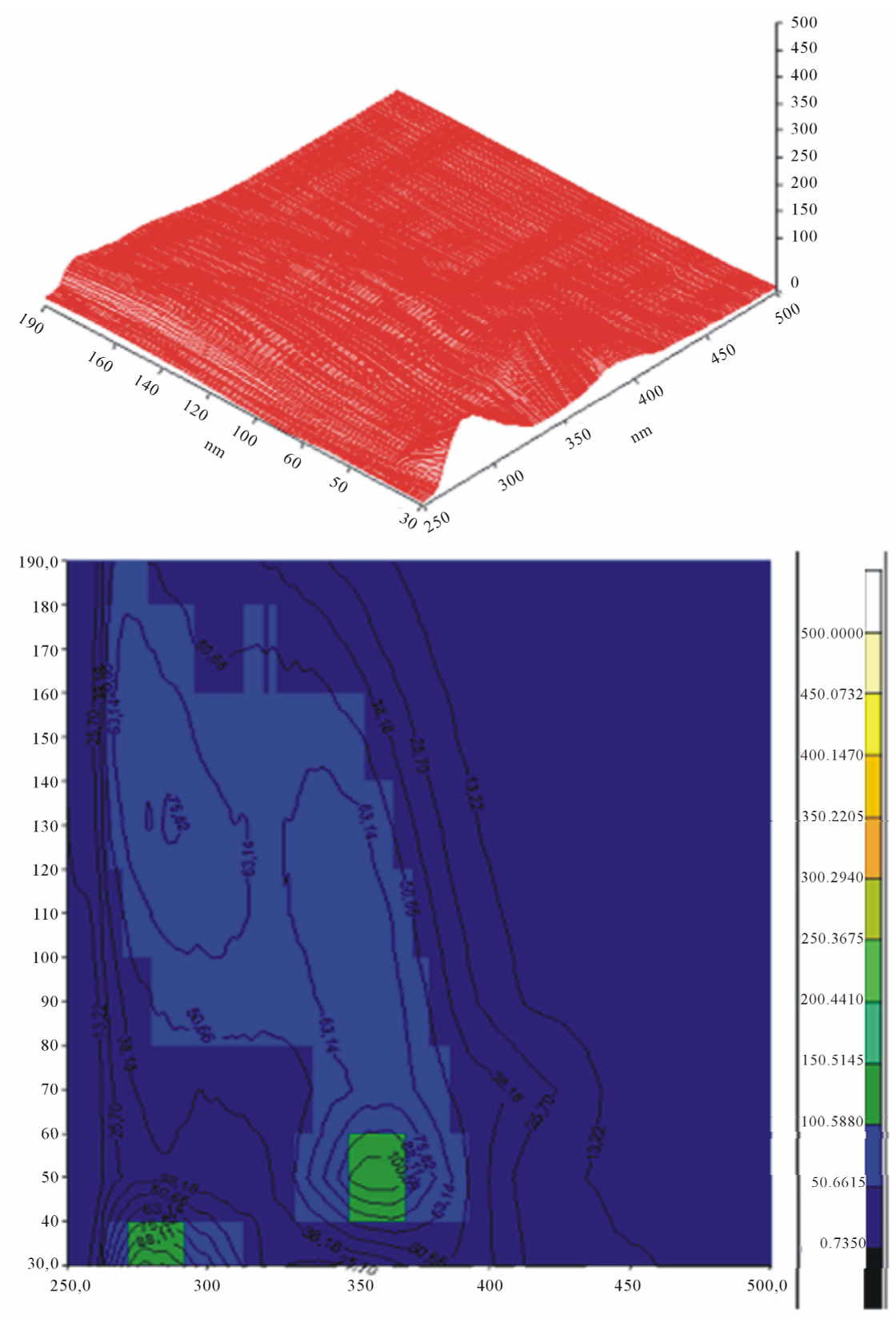

Figure 2. Synchronous fluorescence fingerprint 3-D plot (above) and topogram (below) of compound $2 \mathrm{~b}(\mathrm{c}=10 \mathrm{nmol} / \mathrm{ml}$ in respiration medium containing $0.2 \%$ DMSO and $1 \mathrm{mM}$ sodium succinate). Excitation slit $=5 \mathrm{~nm}$, emission slit $=10 \mathrm{~nm}$, scan speed $=200 \mathrm{~nm} / \mathrm{min}$. The fluorescence maxima of topogram $\left(\lambda_{\mathrm{ex}}=365 \mathrm{~nm} / \Delta \lambda=50 \mathrm{~nm}, \mathrm{~F}=116 ; \lambda_{\mathrm{ex}}=280 \mathrm{~nm} / \Delta \lambda=30 \mathrm{~nm}, \mathrm{~F}=\right.$ 118). 

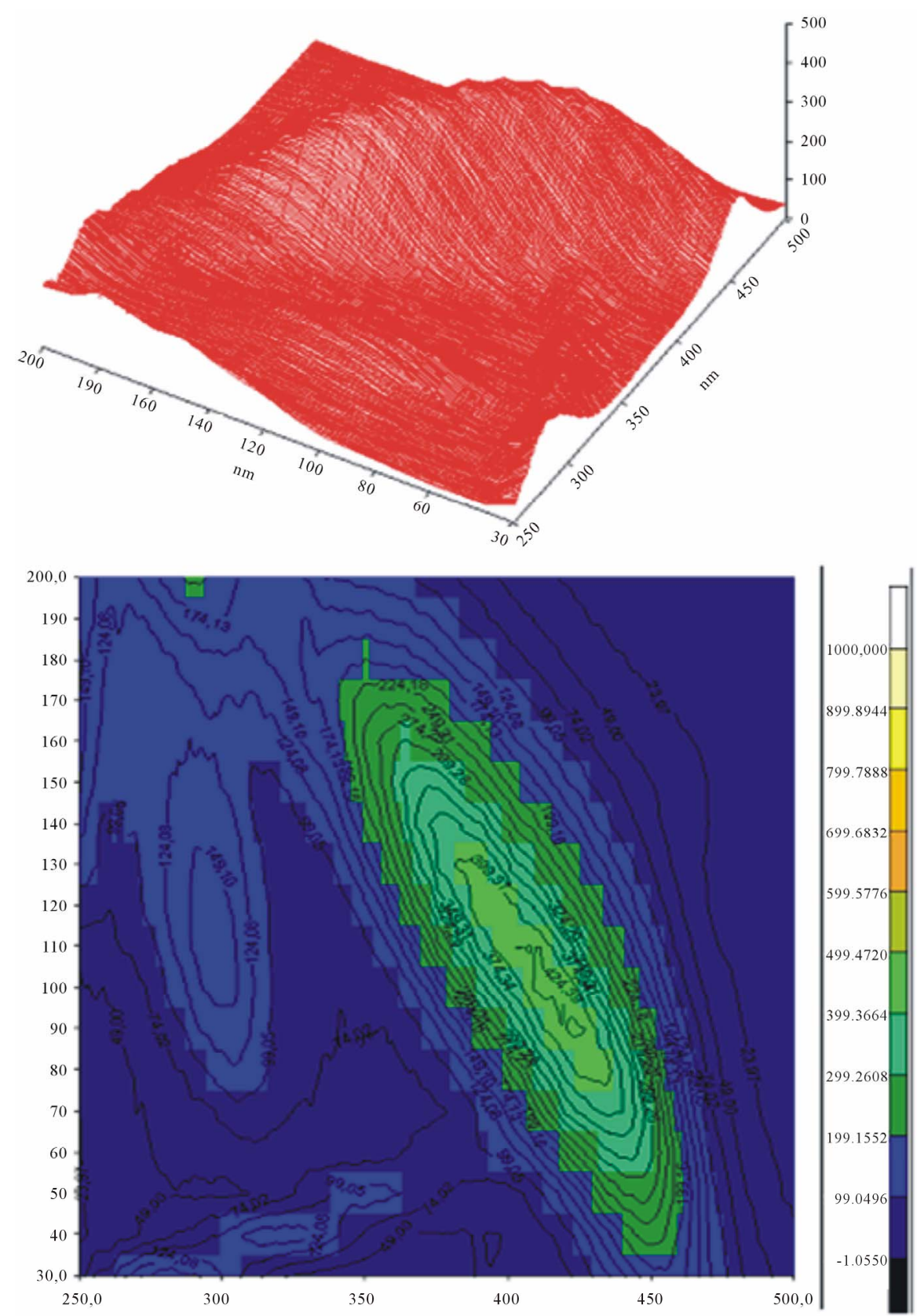

Figure 3. Synchronous fluorescence fingerprint 3-D plot (above) and topogram (below) of compound $2 \mathrm{c}(\mathrm{c}=10 \mathrm{nmol} / \mathrm{ml}$ in respiration medium containing $0.2 \%$ DMSO and $1 \mathrm{mM}$ sodium succinate). Excitation slit $=5 \mathrm{~nm}$, emission slit $=10 \mathrm{~nm}$, scan speed $=1200 \mathrm{~nm} / \mathrm{min}$. The fluorescence maximum of topogram $\left(\lambda_{\mathrm{ex}}=415 \mathrm{~nm} / \Delta \lambda=100 \mathrm{~nm}, \mathrm{~F}=500\right)$.

$(\Delta \lambda=20,40,60,80,100,120,140,160,180,200 \mathrm{~nm})$ between both excitation and emission monochromators. Fluorescence polarization (FP) measurements [15,16] of the studied chalcones (1),c and $\mathbf{2 b}, \mathbf{c})$ with bovine (BSA) and human (HSA) serum albumins (Figures 4 and 5) as well as with rat liver mitochondria (RLM) (Figure 6) were performed at their excitation/emission maximum for a period of 30 minutes at ambient temperature. The protein concentration of the investigated mixtures (BSA,
HSA, RLM) was $2 \mu \mathrm{g} / \mathrm{ml}$. As references, FP of non/ treated BSA, HSA and RLM in respiration medium containing $1 \mathrm{mM}$ sodium succinate were determined at the excitation/emission maxima of the respective chalcones. FP measurements studying interaction of $2 \mathbf{c}$ with yeast cytoplasm (YC) and yeast mitochondria (YM) were performed under similar conditions. The results of these latter measurements (together with those of $2 \mathbf{c}$ with BSA, HSA and RLM) are shown on Figure 7. 


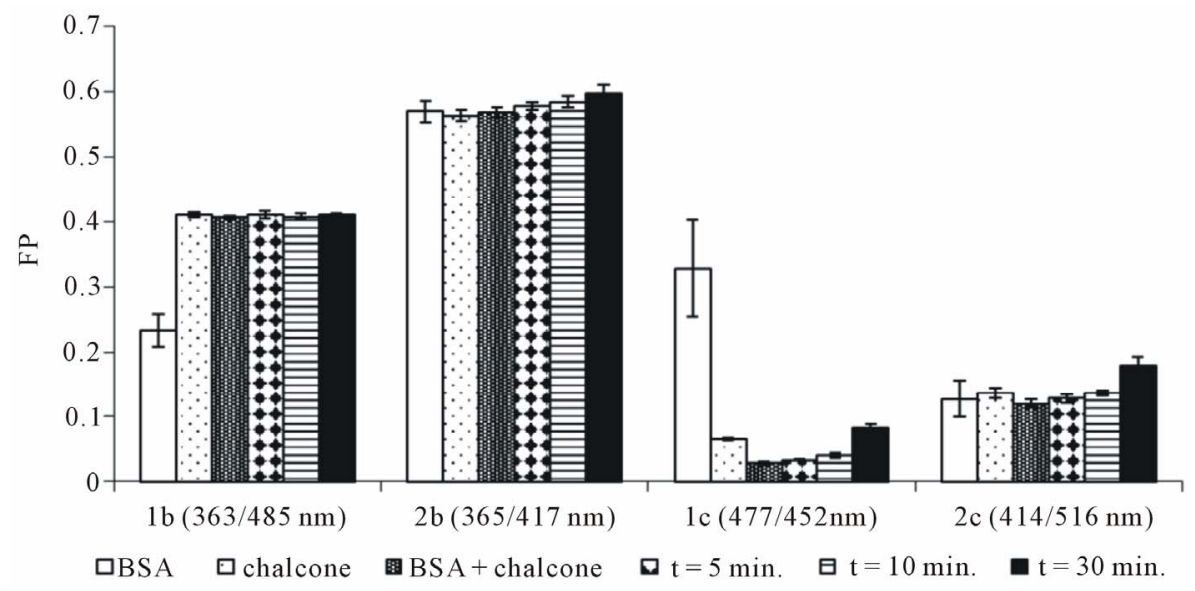

Figure 4. Fluorescence polarization (FP) values of chalcone $(1 \mathrm{~b}, 1 \mathrm{c})$ and benzosuberone $(2 \mathrm{~b}, 2 \mathrm{c})$ with methoxy- and dimethylamino-substituents recorded in respiration medium containing $0.2 \%$ DMSO and $1 \mathrm{mM}$ sodium succinate without (2nd bar) and in the presence of bovine serum albumin (BSA) (3rd - 6th, bars). Protein content of the bovine serum albumin containing samples is $2 \mu \mathrm{g} / \mathrm{ml}$. Fluorescence polarization measurement of each compound (2nd bar)—and the corresponding reference bovine serum albumin (1st bar) — has been performed at the respective excitation/emission maxima of studied molecules (Table 1).

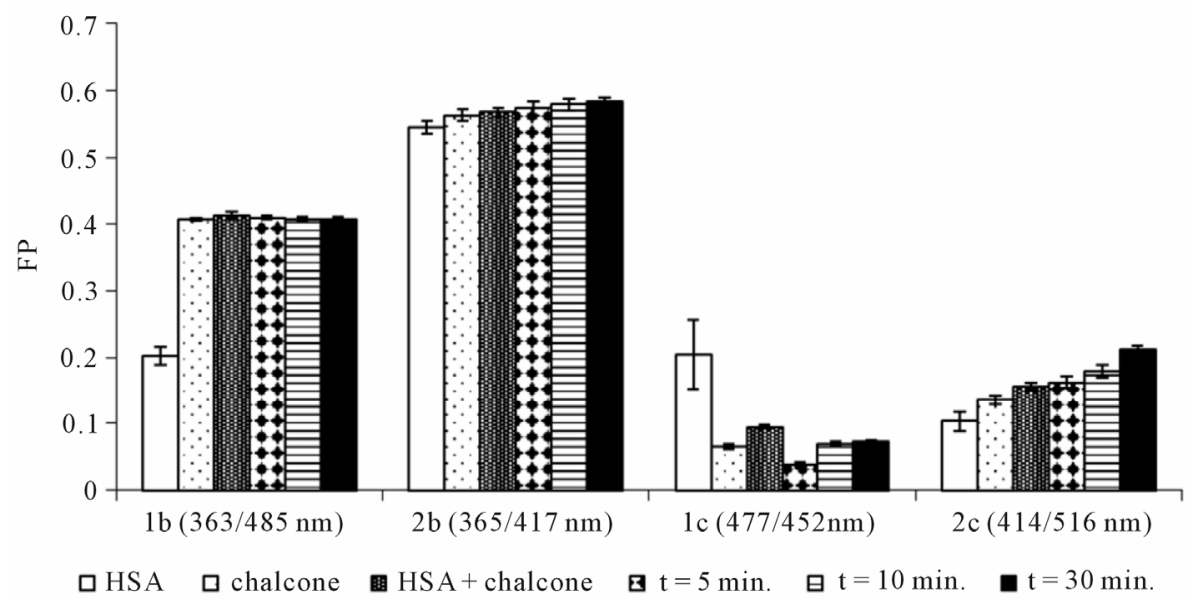

Figure 5. Fluorescence polarization (FP) values of chalcone $(1 \mathrm{~b}, 1 \mathrm{c})$ and benzosuberone $(2 \mathrm{~b}, 2 \mathrm{c})$ with methoxy- and dimethylamino-substituents recorded in respiration medium containing $0.2 \%$ DMSO and $1 \mathrm{mM}$ sodium succinate without (2nd bar) and in the presence of human serum albumin (HSA) (3rd - 6th bars). Protein content of the human serum albumin containing samples is $2 \mu \mathrm{g} / \mathrm{ml}$. Fluorescence polarization measurement of each compound ( $2 \mathrm{nd}$ bar)—and the corresponding reference human serum albumin (1st bar) — has been performed at the respective excitation/emission maxima of studied molecules (Table 1).

\section{Results and Discussion}

The individual $\mathbf{1 b}, \mathbf{1 c}, \mathbf{2 b}$ and $\mathbf{2 c}$ were characterized by excitation and emission fluorescence spectra recorded in respiration medium containing $1 \%$ DMSO a $1 \mathrm{mM}$ succinate. The maxima of the excitation and emission fluorescence spectra of the compounds are summarized in Table 1. Comparison of these spectroscopic characteristics of the two series (1 and 2) shows that the fluorescence intensities of the benzosuberones (2) are lower than those of the corresponding open-chain derivatives (1). Similar observation could be made by comparison of some monomethoxy-substituted tetralone and benzosuberone derivatives, showing the benzosuberones the lower fluorescence intensities [9]. For further characterization of the biologically most promising benzosuberone derivatives (2b and $\mathbf{2} \mathbf{c}$ ), synchronous fluorescence fingerprint (3-D plot) of the compounds were recorded and are shown on Figures $\mathbf{2}$ and 3, respectively. In order to investigate possible interaction of compounds $\mathbf{1 b}, \mathbf{c}$ and 2b,c with BSA, HSA and rat liver mitochondria (RLM) fluorescence characteristics of the proteins were determined in the presence or in the absence of the investigated compounds. 


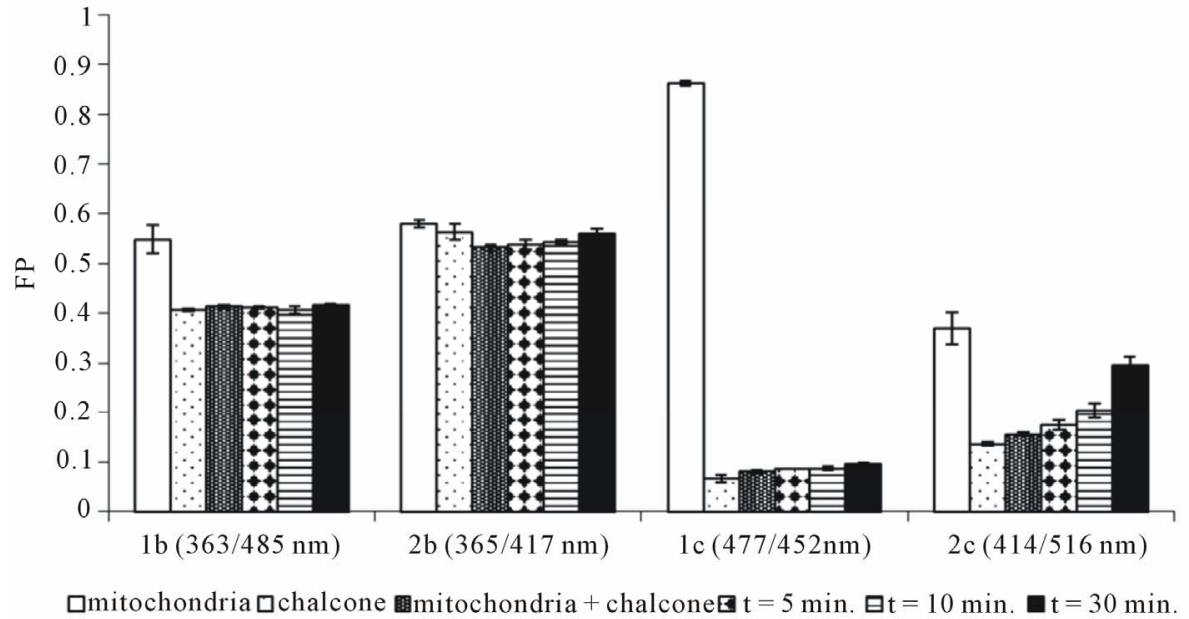

Figure 6. Fluorescence polarization (FP) values of chalcone $(1 \mathrm{~b}, 1 \mathrm{c})$ and benzosuberone $(2 \mathrm{~b}, 2 \mathrm{c})$ with methoxy- and dimethylamino-substituents recorded in respiration medium containing $0.2 \%$ DMSO and $1 \mathrm{mM}$ sodium succinate without (2nd bar) and in the presence of rat liver mitochondria (RLM) (3rd - 6th bars). Protein content of the mitochondria containing samples is $2 \mu \mathrm{g} / \mathrm{ml}$. Fluorescence polarization measurement of each compound (2nd bar) — and the corresponding reference mitochondria samples (1st bar) — has been performed at the respective excitation/emission maxima of studied molecules (Table 1).

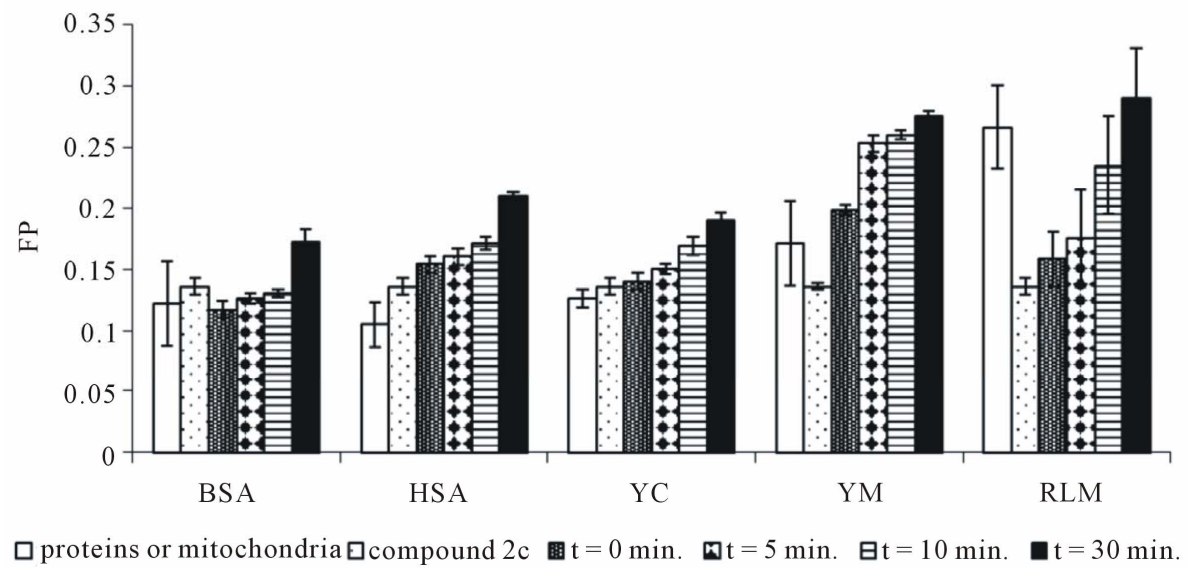

Figure 7. Fluorescence polarization (FP) values of compound $2 \mathrm{c}$ recorded in respiration medium containing $0.2 \%$ DMSO and $1 \mathrm{mM}$ sodium succinate without (2nd bar) and in the presence of natural fluorophores (BSA, HSA, yeast cytoplasm YMC, yeast mitochondria YM, rat liver mitochondria RLM (3rd - 6th bars). Protein content of the mitochondria containing samples as well as BSA, HSA and yeast cytoplasm is $2 \mu \mathrm{g} / \mathrm{ml}$. Fluorescence polarization measurement of each compound (2nd bar) -and the corresponding reference BSA, HSA and mitochondria samples (1st bar)—have been performed at the respective $(415 / 516) \mathrm{nm}$ excitation/emission maxima of $2 \mathrm{c}$ molecule.

The recorded excitation and emission fluorescence spectra of the proteins $(2 \mu \mathrm{g} / \mathrm{ml}$ BSA, HSA or RLM) revealed that these biological materials show strong fluorescence emission with the approximately the same maxima (ex 280/em $346 \mathrm{~nm}$ ) of fluorescence (Tables 2-4). The fluorescence of a folded protein is a mixture of the fluorescence from individual aromatic residues. Most of the emissions are due to excitation of tryptophan residues $(280 / 348 \mathrm{~nm})$, with a few emissions due to tyrosine $(274 / 303 \mathrm{~nm})$ and phenylalanine $(257 / 302 \mathrm{~nm})$ [17]. Addition of chalcones $\mathbf{1}$ and $\mathbf{2}$ to the biological materials resulted in decrease of the fluorescence intensities accompanied by a weak hypsochromic (blue) shift of the maximum emission wavelengths in the fluorescence spectra (Tables 2-4). The hypsochromic shifts indicated that the binding of the chalcones was associated with some change in the immediate molecular environment (polarity, proximity of other residues) of the tryptophan residues and the interactions resulted in quenching of their intrinsic fluorescence $[18,19]$. The interaction forces between proteins and compounds $\mathbf{1}$ and $\mathbf{2}$ may include electrostatic interactions, multiple hydrogen 
Table 2. Fluorescence properties of synthetic chalcones $(1 \mathrm{~b}, 1 \mathrm{c})$ and their cyclic chalcone analogues $(2 \mathrm{~b}, 2 \mathrm{c})$ with bovine serine albumin (BSA) in respiration medium containing $0.2 \%$ DMSO a $1 \mathrm{mM}$ succinate. Concentrations of studied compounds were $10 \mathrm{nmol} / \mathrm{l}$, concentration of bovine serum albumin was $2 \mu \mathrm{g} / \mathrm{ml}$ with excitation/emission maximum (278/340) $\mathrm{nm}$.

\begin{tabular}{cccccc}
\hline Fluorophores & $\begin{array}{c}\text { Excitation maximum } \\
\boldsymbol{\lambda}_{\text {ex }}(\mathbf{n m})\end{array}$ & $\begin{array}{c}\text { Fluorescence intensity } \\
\mathbf{F}_{\text {ex }}\end{array}$ & $\begin{array}{c}\text { Emission maximum } \\
\boldsymbol{\lambda}_{\mathrm{em}}(\mathbf{n m})\end{array}$ & $\begin{array}{c}\text { Fluorescence intensity } \\
\mathbf{F}_{\mathrm{em}}\end{array}$ & $\begin{array}{c}\text { Fluorescence } \\
\text { polarization FP }\end{array}$ \\
\hline $\mathbf{1 b}+\mathbf{B S A}$ & 278 & 243 & 339 & 243 & 0.41 \\
$\mathbf{2 b}+\mathbf{B S A}$ & 279 & 169 & 337 & 170 & 0.597 \\
$\mathbf{1 c}+\mathbf{B S A}$ & 278 & 225 & 340 & 226 & 0.083 \\
$\mathbf{2 c}+\mathbf{B S A}$ & 279 & 271 & 338 & 271 & 0.178 \\
$\mathbf{B S A}$ & 278 & 321 & 341 & 317 & 0.127 \\
\hline
\end{tabular}

Table 3. Fluorescence properties of synthetic chalcones $(1 \mathrm{~b}, 1 \mathrm{c})$ and their cyclic chalcone analogues $(2 \mathrm{~b}, 2 \mathrm{c})$ with human serine albumin (HSA) in respiration medium containing $0.2 \%$ DMSO a 1-mM succinate. Concentrations of studied compounds were $10 \mathrm{nmol} / \mathrm{l}$, concentration of human serum albumin was $2 \mu \mathrm{g} / \mathrm{ml}$ with excitation/emission maximum $(277 / 341) \mathrm{nm}$.

\begin{tabular}{cccccc}
\hline Fluorophores & $\begin{array}{c}\text { Excitation maximum } \\
\lambda_{\mathrm{ex}}(\mathbf{n m})\end{array}$ & $\begin{array}{c}\text { Fluorescence intensity } \\
\mathbf{F}_{\mathrm{ex}}\end{array}$ & $\begin{array}{c}\text { Emission maximum } \\
\boldsymbol{\lambda}_{\mathrm{em}}(\mathbf{n m})\end{array}$ & $\begin{array}{c}\text { Fluorescence Maximum } \\
\mathbf{F}_{\mathrm{em}}\end{array}$ & $\begin{array}{c}\text { Fluorescence } \\
\text { polarization FP }\end{array}$ \\
\hline $\mathbf{1 b}+$ HSA & 278 & 341 & 340 & 341 & 0.407 \\
$\mathbf{2 b}+$ HSA & 278 & 287 & 338 & 288 & 0.584 \\
$\mathbf{1 c}+$ HSA & 278 & 222 & 341 & 222 & 0.072 \\
$\mathbf{2 c}+$ HSA & 278 & 324 & 339 & 324 & 0.211 \\
HSA & 277 & 354 & 342 & 355 & 0.103 \\
\hline
\end{tabular}

Table 4. Fluorescence properties of synthetic chalcones $(1 \mathrm{~b}, 1 \mathrm{c})$ and their cyclic chalcone analogues $(2 \mathrm{~b}, 2 \mathrm{c})$ with rat liver mitochondria (RLM) in respiration medium containing $0.2 \%$ DMSO a 1-mM succinate. Concentrations of studied compounds were $10 \mathrm{nmol} / \mathrm{l}$, concentration of rat liver mitochondria were $2 \mu \mathrm{g} / \mathrm{ml}$ with excitation/emission maximum (277/341) $\mathrm{nm}$.

\begin{tabular}{cccccc}
\hline Fluorophores & $\begin{array}{c}\text { Excitation maximum } \\
\boldsymbol{\lambda}_{\mathbf{e x}}(\mathbf{n m})\end{array}$ & $\begin{array}{c}\text { Fluorescence intensity } \\
\mathbf{F}_{\mathbf{e x}}\end{array}$ & $\begin{array}{c}\text { Emission maximum } \\
\boldsymbol{\lambda}_{\mathrm{em}}(\mathbf{n m})\end{array}$ & $\begin{array}{c}\text { Fluorescence intensity } \\
\mathbf{F}_{\text {em }}\end{array}$ & $\begin{array}{c}\text { Fluorescence } \\
\text { Polarization FP }\end{array}$ \\
\hline $\mathbf{1 b}+$ Mit & 280 & 384 & 345 & 385 & 0.416 \\
$\mathbf{2 b}+$ Mit & 279 & 315 & 342 & 314 & 0.559 \\
$\mathbf{1 c}+$ Mit & 280 & 358 & 345 & 360 & 0.096 \\
$\mathbf{2 c}+$ Mit & 279 & 398 & 341 & 399 & 0.296 \\
Mitochondria & 280 & 620 & 346 & 622 & 0.370 \\
\hline
\end{tabular}

bonds, van der Waals interactions, hydrophobic and steric contacts, mentioning only the most important ones [20]. The week hypsochromic shifts are indicative for increasing hydrophobicity of the tryptophane residues [19]. In accord with our previous UV-VIS results, it was compounds $\mathbf{2 b}$ and $\mathbf{2 c}$ that showed to develop the stronger interaction with the investigated proteins [9].

In order to further investigate the nature of interaction of compounds $\mathbf{1 b}, \mathbf{c}$ and $\mathbf{2 b , \mathbf { c }}$ with BSA, HSA and rat liver mitochondria (RLM) fluorescence polarization (FP) measurements were performed. The measurements were run at the excitation and the emission wavelength maxima of each chalcone determined in the previous experiments (Table 1).
Change of fluorescence polarization was determined after addition of the proteins to the above described solutions of compounds 1 and 2 at the 0-, 5-, 10-, 20- and 30 -min timepoints. As references, fluorescence polarization of each investigated compound as well as the proteins in the respiration medium containing 1\% DMSO and $1 \mathrm{mM}$ sodium succinate was determined at the corresponding excitation and emission wavelength maxima (Figures 4-6). Application of fluorescence polarization (FP) provides information about the molecular motion of UV light excited molecules and it is valuable tool for investigation of interaction of biological membranes with small fluorescent molecules [15,16,21]. As it is shown on Figures 4-6, the methoxy-substituted derivatives (1b and 
Table 5. Characteristic fluorescence parameters of synthetic $2 \mathrm{c}$ and different natural fluorophores: bovine serum albumin (BSA), human serum albumin (HSA), rat liver mitochondria (RLM), yeast cytoplasm (YC) and yeast mitochondria (YM) determined in respiration medium and $1 \mathrm{mM}$ sodium succinate.

\begin{tabular}{cccccccc}
\hline Fluorophore & $\begin{array}{c}\text { Concentration } \\
(\boldsymbol{\mu m o l} / \mathbf{m l})\end{array}$ & $\begin{array}{c}\boldsymbol{\lambda}_{\mathbf{e x}} \\
(\mathbf{n m})\end{array}$ & $\begin{array}{c}\mathbf{F} \\
\left(\boldsymbol{\lambda}_{\mathbf{e x}}\right)\end{array}$ & $\begin{array}{c}\boldsymbol{\lambda}_{\text {em }} \\
(\mathbf{n m})\end{array}$ & $\begin{array}{c}\mathbf{F} \\
\left(\boldsymbol{\lambda}_{\mathbf{e m}}\right)\end{array}$ & $\begin{array}{c}\text { Stokes shift } \\
(\mathbf{n m})\end{array}$ & $\begin{array}{c}\text { Fluorescence } \\
\mathbf{p o l a r i z a t i o n} \mathbf{F P} \pm \mathbf{s}\end{array}$ \\
\hline $2 \mathrm{c}$ & 0.010 & 415 & 580 & 516 & 590 & 101 & $0.090 \pm 0.007$ \\
BSA & 2 & 278 & 321 & 341 & 317 & 65 & $0.127 \pm 0.028$ \\
HSA & 2 & 277 & 354 & 342 & 355 & 65 & $0.103 \pm 0.014$ \\
YC & 2 & 279 & 550 & 345 & 556 & 66 & $0.127 \pm 0.005$ \\
YM & 2 & 280 & 700 & 346 & 715 & 66 & $0.180 \pm 0.032$ \\
RLM & 2 & 280 & 620 & 346 & 625 & 66 & $0.270 \pm 0.032$ \\
\hline
\end{tabular}

2b) displayed an elevated fluorescence polarization on mixing with mitochondria at the $\mathrm{t}=0$ time points. This indicates an instant interaction of the molecules with the mitochondrial membrane surface that can slow down molecular motion of the excited chalcone analogues. This observation is in agreement with the results of our previous studies [9]. Methoxy substituted compounds (1b and $\mathbf{2 b}$ ) displayed higher fluorescent polarization values than the dimethylamino substituted compounds (1c and 2c). As it is shown in (Figure 7, Table 5), investigated 2c displayed an elevated fluorescence polarization (FP) on mixing with BSA, HSA, RLM, as well as with YC and $\mathrm{YM}$ at the $\mathrm{t}=0$ time point. This indicates an instant interaction of the $\mathbf{2 c}$ with the respective macromolecules that slows down molecular motion of the excited chalcones. During the 30-minute period the initial FP values showed a slight, continuous increase-similar to the previously investigated seven membered cyclic chalcone analogue E-2-(4'-methoxybenzylidene)-1-benzosuberone [7].

These latter observations might be the consequence of gradual incorporation of the lipophilic $2 \mathrm{c}$ into the macromoleculs and/or the mitochondrial membranes, which decreases the conformational mobility of the molecules [9, 21-23].

\section{Conclusion}

In this work, the interaction of five flavonoids with BSA was studied by fluorescence and UV-visible absorption spectroscopy. The binding reaction was spontaneous, and hydrophobic interaction played a major role in the reaction. The obtained results provide useful knowledge on pharmacological applications of flavonoids and valuable information for designing of new drugs.

\section{Acknowledgements}

This study was supported by the Austrian Science and
Research Liaison Office (ASO) grant, the VEGA 1/0999/ 11 grant, and the Faculty of Medicine Research Fund (PTE AOK-KA-2013/20), (University of Pécs). The authors express their grateful acknowledge to Irmgard Schuiki (Institute of Biochemistry, Technical University of Graz) for isolating yeast cytoplasm and yeast mitochondria.

\section{REFERENCES}

[1] F. A. Tomas-Berbeeren and M. N. Clifford, "Flavanones, Chalcones and Dihydrochalcones-Nature, Occurrence and Dietary Burden," Journal of the Science of Food and Agriculture, Vol. 80, No. 7, 2000, pp. 1073-1080. doi:10.1002/(SICI)1097-0010(20000515)80:7<1073::AID -JSFA568>3.0.CO;2-B

[2] J. E. Middleton, C. Kandaswami and T. C. Theoharides, "The Effects of Plant Flavonoids on Mammalian Cells: Implications for Inflammation, Heart Disease, and Cancer," Pharmacological Reviews, Vol. 52, No. 4, 2000, pp. 673-751.

[3] F. Depeint, J. M. Gee, G. Williamson and I. T. Johnson, "Evidence for Consistent Patterns between Flavonoid Structures and Cellular Activities," Proceedings of the Nutrition Society, Vol. 61, No. 1, 2002, pp. 97-103. doi:10.1079/PNS2001133

[4] M. L. Go, X. Wu and X. L. Liu, "Chalcones: An Update on Cytotoxic and Chemoprotective Properties," Current Medicinal Chemistry, Vol. 12, No. 4, 2005, pp. 483-499.

[5] J. R. Dimmock, N. M. Kandepu, A. J. Nazarali, T. P. Kowalchuk, N. Motaganahalli, J. W. Quail, P. A. Mykytiuk, G. F. Audette, L. Prasad, P. Perjési, T. M. Allen, C. L. Santos, J. Szydlowski, E. DeClercq and J. Balzarini, "Conformational and Quantitative Structure-Activity Relationship Study of Cytotoxic 2-Arylidenebenzocycloalkanones," Journal of Medicinal Chemistry, Vol. 42, No. 8, 1999, pp. 1358-1366. doi:10.1021/jm9806695

[6] J. R. Dimmock, G. A. Zello, E. O. Oloo, J. W. Quail, H.-B. Kraatz, P. Perjési, F. Aradi, K. Takács-Novák, T. M. Allen, C. L. Santos, J. Balzarini, E. DeClercq and J. P. Stables, "Correlation between Cytotoxicity and Topogra- 
phy of Some 2-Arylidenebenzocyclanones Determined by X-Ray Crystallography," Journal of Medicinal Chemistry, Vol. 45, No. 14, 2002, pp. 3103-3111.

doi:10.1021/jm010559p

[7] P. Perjési, U. Das, E. De Clercq, J. Balzarini, M. Kawase, H. Sakagami, J. P. Stables, T. Loránd, Z. Rozmer and J. R. Dimmock, "Design, Synthesis and Antiproliferative Activity of Some 3-Benzylidene-2,3-dihydro-1-ben-zopyran-4-ones Which Display Selective Toxicity for Malignant Cells," European Journal of Medicinal Chemistry, Vol. 43, No. 4, 2008, pp. 839-845. doi:10.1016/i.ejmech.2007.06.017

[8] K. Fodor, V. Tomečková, T. Koszegi, I. Kron and P. Perjési, "(E)-2-Benzylidenecyclanones: Part VI. Solvent Effect on the UV and Fluorescence Properties of Some Chalcones and Their Cyclic Analogues. Interaction of 4-Dimethylaminochalcones with Bovine and Human Serum Albumin: A UV-VIS Study," Monatshefte für Chemie, Vol. 142, No. 5, 2011, pp. 463-468. doi:10.1007/s00706-011-0463-0

[9] V. Tomečková, P. Perjési, J. Guzy, J. Kusnir, Z. Chovanová, Z. Chavková and M. Mareková, "Comparison of Effect of Selected Synthetic Chalcone Analogues on Mitochondrial Outer Membrane Determined by Fluorescence Spectroscopy," Journal of Biochemical and Biophysical Methods, Vol. 61, No. 1-2, 2004, pp. 135-141. doi:10.1016/j.jbbm.2004.04.010

[10] P. Perjési, T. Nusser, G. Tarczay and P. Sohar, "E-2-Benzylidenebenzocycloalkanones. Stereostructure and NMR Spectroscopic Investigation," Journal of Molecular Structure, Vol. 479, No. 1, 1999, pp. 13-19. doi:10.1016/S0022-2860(98)00805-9

[11] D. Johnson and H. Lardy, "Isolation of Rat Liver and Kidney Mitochondria," Methods in Enzymology, Vol. 10, 1967, pp. 94-96. doi:10.1016/0076-6879(67)10018-9

[12] M. M. Bradford, "A Rapid and Sensitive for the Quantification of Microgram Quantities of Protein Utilizing the Principle of Protein-Dye Binding," Analytical Biochemistry, Vol. 72, No. 1-2, 1976, pp. 248-254. doi:10.1016/0003-2697(76)90527-3

[13] E. Zinser and G. Daum, "Isolation and Biochemical Characterisation of Organelles Form the Yeast, Saccharomyces cerevisiae," Yeast, Vol. 11, No. 6, 1995, pp. 493-

\section{6. doi: $10.1002 /$ yea. 320110602}

[14] O. H. Lowry, N. J. Rosebrough, A. L. Farr and R. Ramdall, "Protein Measurement with the Folin Phenol Reagent," Journal of Biological Chemistry, Vol. 193, No. 1, 1951, pp. 265-275.

[15] W. J. Checovich, R. E. Bolger and T. Burke, "Fluorescence Polarization-A New Tool for Cell and Molecular Biology," Nature, Vol. 375, 1995, pp. 253-256. doi: $10.1038 / 375254 \mathrm{a} 0$

[16] B. J. Litman and Y. Barenholz, "Fluorescence Probe: Difenylhexatriene," Methods in Enzymology, Vol. 81, 1982, pp. 678-685. doi:10.1016/S0076-6879(82)81093-8

[17] J. R. Lakowicz, "Principles of Fluorescence Spectroscopy," 2nd Edition, Kluwer Academic/Plenum Publishers, New York, 1999. doi:10.1007/978-1-4757-3061-6

[18] J. T. Vivian and P. R. Callis, "Mechanisms of Tryptophan Fluorescence Shifts in Proteins," Biophysical Journal, Vol. 80, No. 5, 2001, pp. 2093-2109. doi:10.1016/S0006-3495(01)76183-8

[19] S. Gorinstein, I. Goshev, S. Moncheva, M. Zemser, M. Weisz, A. Caspi, I. Libman, H. T. Lerner, S. Trakhtenberg and O. Martín-Belloso, "Intrinsic Tryptophan Fluorescence of Human Serum Proteins and Related Conformational Changes," Journal of Protein Chemistry, Vol. 19, No. 8, 2000, pp. 637-642. doi:10.1023/A:1007192017291

[20] D. Leckband, "Measuring the Forces that Control Protein Interactions," Annual Review of Biophysics and Biomolecular Structure, Vol. 29, 2000, pp. 1-26. doi:10.1146/annurev.biophys.29.1.1

[21] L. A. Sklar, "Chapter 3. Fluorescence Polarization Studies of Membrane Fluidity: Where Do We Go from Here?" In: Biomembranes, Plenum Press, New York, 1984, pp. 99-131.

[22] M. Shinitzky and Y. Berenholz, "Fluidity Parameters of Lipid Regions Determined by Fluorescence Polarization," Biochimica et Biophysica Acta, Vol. 515, No. 4, 1978, pp. 367-394. doi:10.1016/0304-4157(78)90010-2

[23] B. H. Havsteen, "The Biochemistry and Medical Significance of the Flavonoids," Pharmacology and Therapeutics, Vol. 96, No. 2-3, 2002, pp. 67-202. doi:10.1016/S0163-7258(02)00298-X 